\title{
Supporting Information for: Repair Rate of Clustered Abasic DNA Lesions by Human Endonuclease: Molecular Bases of Sequence Specificity
}

Hugo Gattuso ${ }^{1,2}$, Elodie Durand ${ }^{1,2}$, Emmanuelle Bignon ${ }^{3,4}$, Christophe Morell ${ }^{4}$, Alexandros G. Georgakilas $^{5, *}$, Elise Dumont ${ }^{3}$, Christophe Chipot ${ }^{1,2,6}$, François Dehez $^{1,2}$, Antonio Monari ${ }^{1,2}$

${ }^{1}$ Université de Lorraine -Nancy, Theory-Modeling-Simulation SRSMC, Vandoeuvre-lès-Nancy, France, ${ }^{2} \mathrm{CNRS}$, Theory-Modeling-Simulation SRSMC, Vandoeuvre-lès-Nancy, ${ }^{3}$ Univ Lyon, Ens de Lyon, CNRS UMR 5182, Université Claude Bernard Lyon 1, Laboratoire de Chimie, F69342, Lyon, France, ${ }^{4}$ Université de Lyon, Institut des Sciences Analytiques UMR 5280, CNRS, Université de Lyon 1, ENS Lyon 5 rue de la Doua F-69100 Villeurbanne France, ${ }^{5}$ Physics Department, School of Applied Mathematical and Physical Sciences, National Technical University of Athens (NTUA), Zografou 15780, Athens, Greece ${ }^{6}$ Department of Physics, University of Illinois at Urbana-Champaign, 1110 West Green Street, Urbana, Illinois 61801, USA 


\section{Computational details:}

The structure of the APE1 protein bound to an AP containing DNA double strand was extracted from the X-ray crystal structure obtained by Mol et al. ${ }^{1}$ (pdb databank code: 1DEW). It is composed of the 278 amino-acids and a 14 bases pairs B-DNA double strand 3'(G)CGTCCXCGACGACG-5', with the first guanine being a dangling base without its facing partner and X the AP site. Clustered AP double strands were manually created from the starting sequence by removing one nucleobase from the complementary strand at the $-3,-1,0,+1$ and +3 distance from the original AP site. Consequently, the sequences have been named seqX-APE1. Single, and clustered AP containing DNA strand were simulated in presence of the protein and as isolated duplexes in solution. The isolated APE1 in absence of any DNA strand was also simulated.

All the systems where placed in TIP3P water boxes ${ }^{2}$ with a buffer of $7 \AA$, charges have been neutralized with $\mathrm{Na}+$ or $\mathrm{Cl}-$ atoms $\left(24 \mathrm{Na}^{+}\right.$ions for isolated DNA, $27 \mathrm{Na}^{+}$ions APE1/DNA complexes, and $2 \mathrm{Cl}^{-}$for APE1 alone in water).

The AP site was parametrized using amber parmf $99 \mathrm{bsc} 0$ parameters ${ }^{3}$, atomic charges were obtained using the RESP procedure ${ }^{4}$.

After an energy minimization of 1000 steps using the conjugate gradient algorithm, the system (excluding the water molecules and ions) was equilibrated by restraining it via a harmonic potential and slowly releasing the restraints through 4 distinct steps of 1 ns. After equilibration a production run of $100 \mathrm{~ns}$ has been performed for all the systems. This time scale appears sufficient to explore the conformational space of the DNA/APE1 complex in particular due to the strong interactions and high rigidity of the aggregates. As concerns the more dynamic solvated 
DNA oligomers the high value of the RMSD is already witnessing important structural deformation reflecting the flexibility of the solvated oligomers. All molecular mechanics and molecular dynamics were conducted using the NAMD program ${ }^{5}$. The amber99 force field ${ }^{6}$ with the recent bsc 1 correction ${ }^{7}$ for DNA backbone dihedral angles were used to model the systems.

The molecular dynamics simulations, integration time step of 2 fs in the NPT ensemble, were carried out using the Langevin dynamics and the Langevin piston ${ }^{8}$ algorithms at a temperature of $300 \mathrm{~K}$ and a pressure of $1 \mathrm{~atm}$.

Long-range electrostatic interactions, represented by the Particle-Mesh-Ewald method ${ }^{9}$ were truncated, as well as Van der Waals ones, for distances greater than $9 \AA$. DNA and DNA-APE1 rendered representations were obtained using $\mathrm{VMD}^{10}$ and Chimera ${ }^{11}$ rendering software. Moreover trajectory analysis where also performed using VMD.

The tweezers (composed of a methionine (MET) and an arginine (ARG)) edges distance, were obtained as the distance between the sulfur atom of MET and the $\gamma$-carbon atom of ARG (Figure 3). Moreover, the 10 central base pairs of the DNA double strands were taken into account for the evaluation of the RMSD. This is to avoid a deviation caused by the highly flexible external bases. 


\begin{tabular}{|c|c|c|c|}
\hline & Name & Type & Charge \\
\hline 1 & $\mathrm{P}$ & $\mathrm{P}$ & 1.1659 \\
\hline 2 & OP2 & $\mathrm{O} 2$ & -0.7761 \\
\hline 3 & OP1 & $\mathrm{O} 2$ & -0.7761 \\
\hline 4 & $\mathrm{O} 5^{\prime}$ & OS & -0.4954 \\
\hline 5 & $\mathrm{C} 5{ }^{\prime}$ & CI & -0.0069 \\
\hline 6 & $\mathrm{H}^{\prime}$ & $\mathrm{H} 1$ & 0.0754 \\
\hline 7 & H5" & $\mathrm{H} 1$ & 0.0754 \\
\hline 8 & $\mathrm{C} 4{ }^{\prime}$ & $\mathrm{CT}$ & 0.2098 \\
\hline 9 & H4' & H1 & 0.0046 \\
\hline 10 & O4' & $\mathrm{OS}$ & -0.4058 \\
\hline 11 & $\mathrm{C} 1{ }^{\prime}$ & $\mathrm{CT}$ & 0.3679 \\
\hline 12 & $\mathrm{O} 1$ & $\mathrm{OH}$ & -0.5959 \\
\hline 13 & H1 & $\mathrm{HO}$ & 0.3761 \\
\hline 14 & $\mathrm{H} 1^{\prime}$ & $\mathrm{HC}$ & 0.02 \\
\hline 15 & C3' & $\mathrm{CT}$ & 0.3259 \\
\hline 11 & H3' & $\mathrm{HC}$ & 0.0562 \\
\hline 12 & $\mathrm{C} 2{ }^{\prime}$ & $\mathrm{CT}$ & -0.286 \\
\hline 13 & $\mathrm{H} 2^{\prime}$ & $\mathrm{HC}$ & 0.0941 \\
\hline 14 & $\mathrm{H} 2$ " & $\mathrm{HC}$ & 0.0941 \\
\hline 15 & O3' & OS & -0.5232 \\
\hline
\end{tabular}

Table S1) Atomic charges (in a.u.) and type specification for the AP site. 


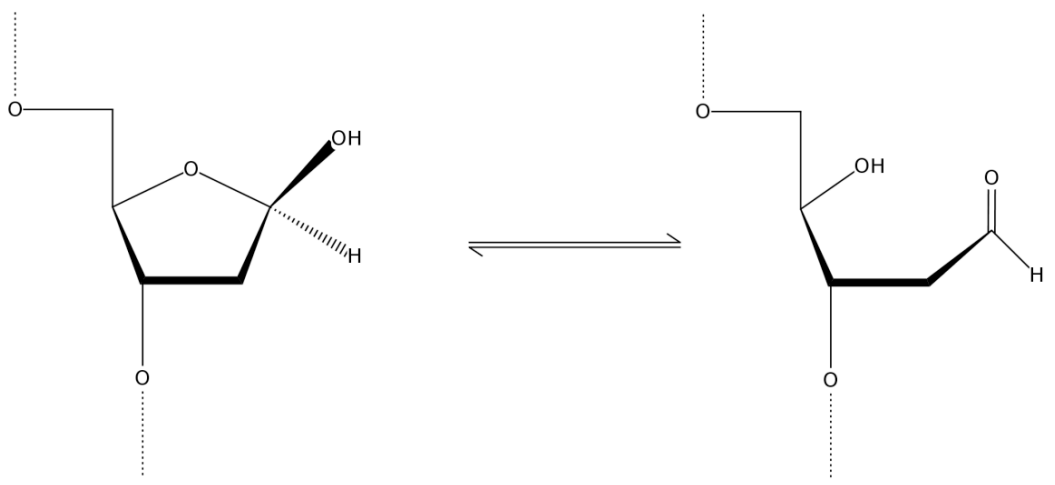

Figure S1) Equilibrium between the open and cyclic conformations of the AP lesion. Note that the equilibrium may produce the two $\mathrm{R}$ and $\mathrm{S}$ enantiomer. Here we represent only the $\mathrm{R}$ enantiomer that has been used in this study. Preliminary calculations have shown however the general global structural behavior of duplexes belonging R or S AP enantiomers.

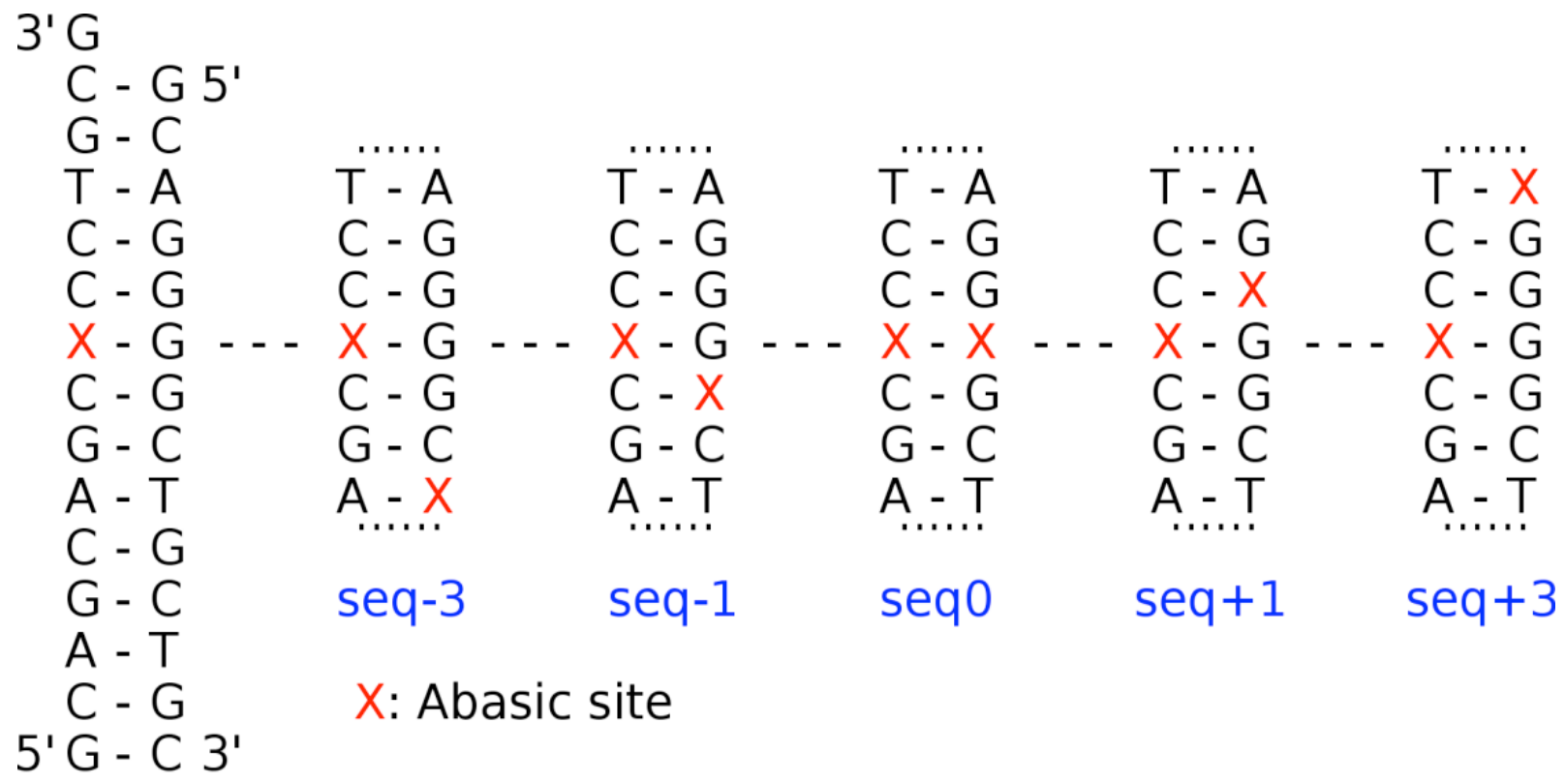

Figure S2) Representation of the investigated DNA sequences. 

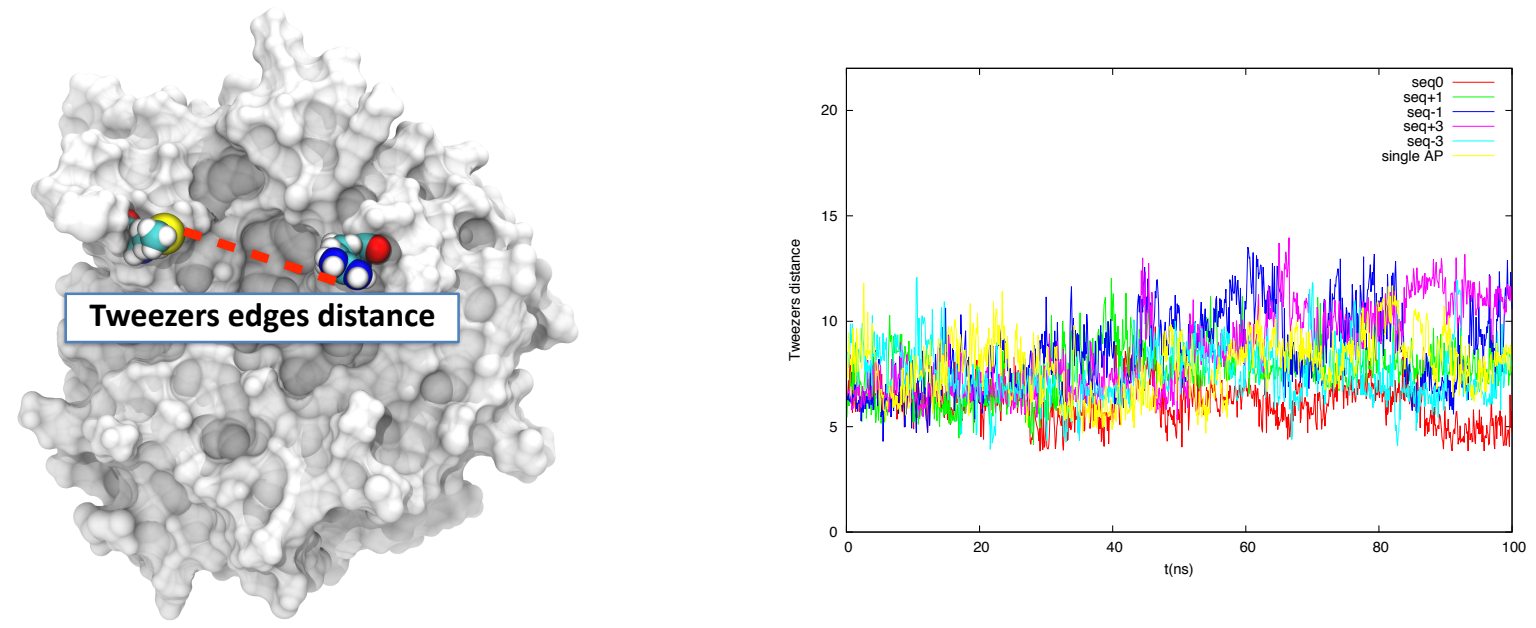

Figure S3) Definition of the tweezers' opening, taken as the distance between the sulfur atoms of the Methionine and the $\gamma$-Carbon atom of the Arginine and time series of the tweezers' edges distance for all the for all the DNA/APE1 complexes simulated in this work.

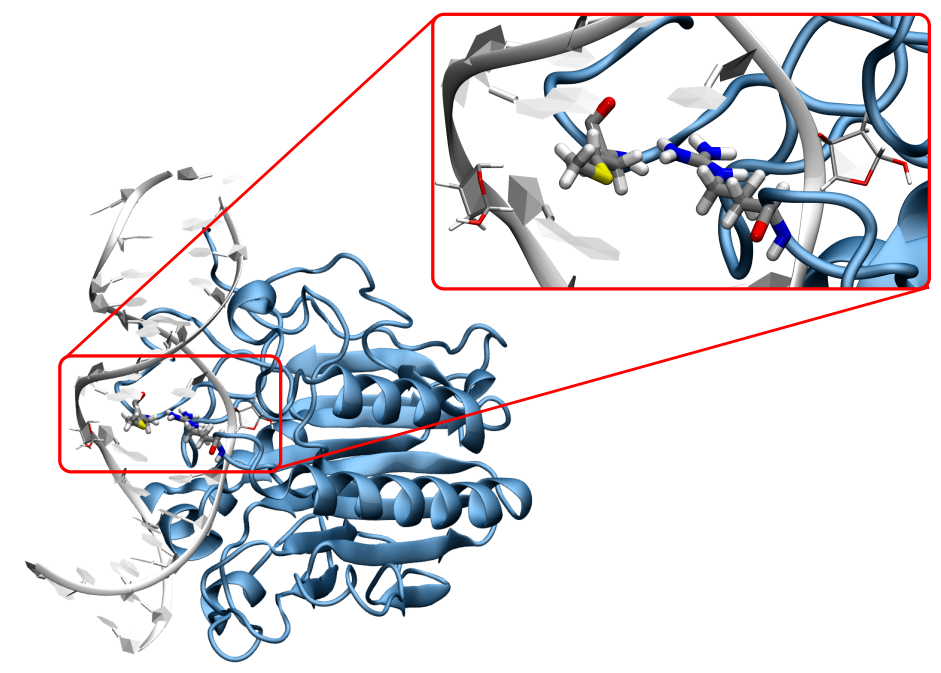

Figure S4) A representative snapshot of the DNA APE1 complex showing the tweezers and its edges. 

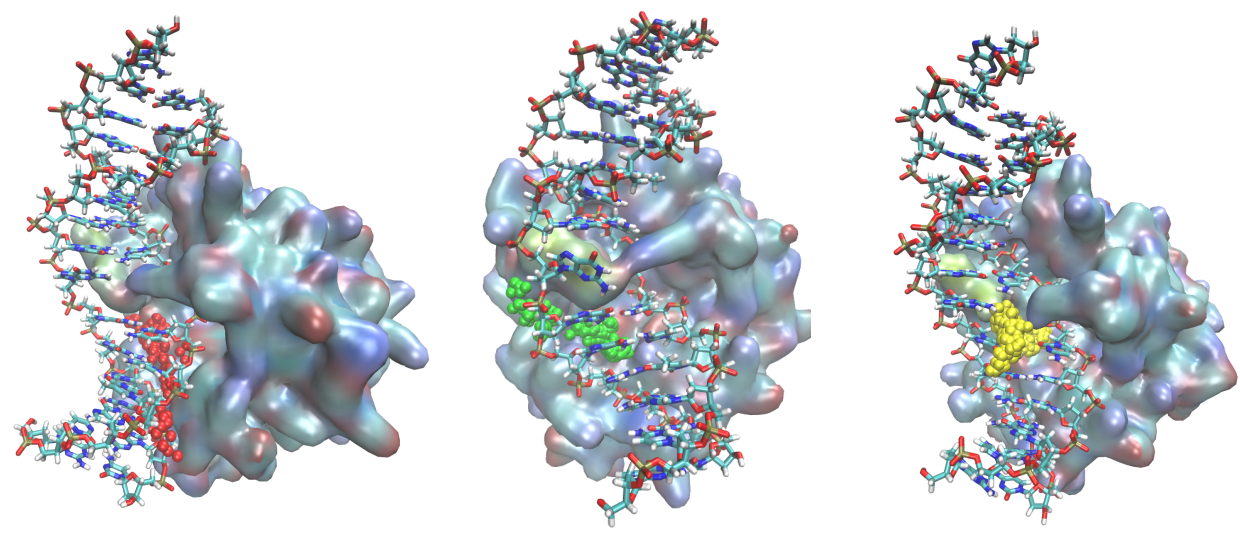

Figure S5) Visualization of the different entrance pathways of the $\mathrm{Na}^{+}$cations in the complex between AP containing DNA strand and APE1. 


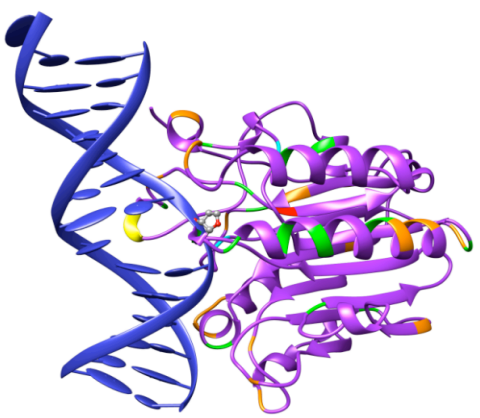

Single AP

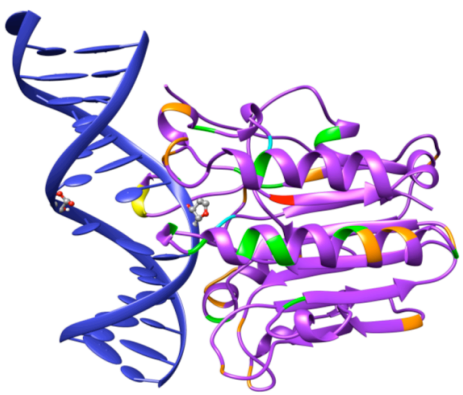

seq-1 - APE1

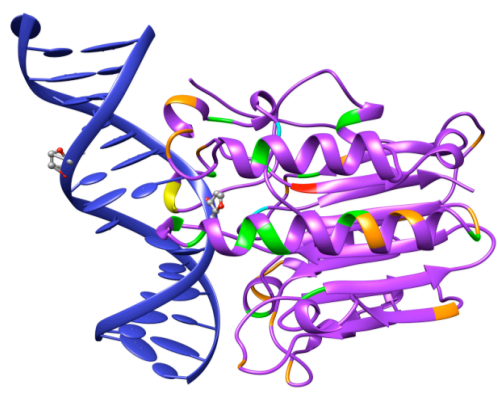

seq-3 - APE1

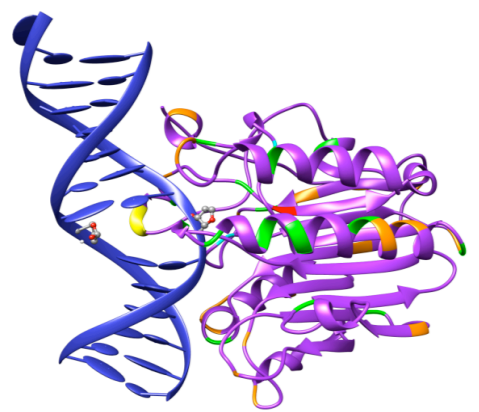

seq0 - APE 1

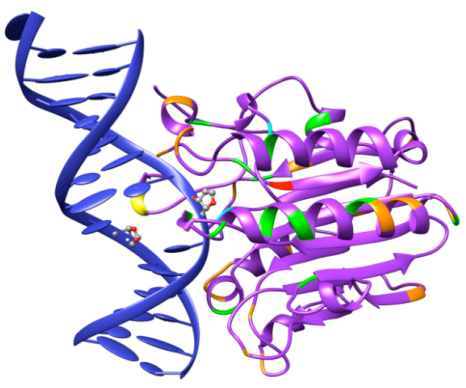

seq $+1-$ APE 1

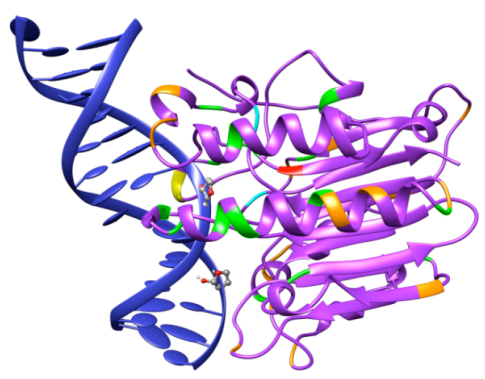

seq $+3-$ APE1

Figure S6) Representative snapshots of DNA/APE1 complexes. DNA and protein are represented in carton. AP sites are evidenced in cpk representation. 

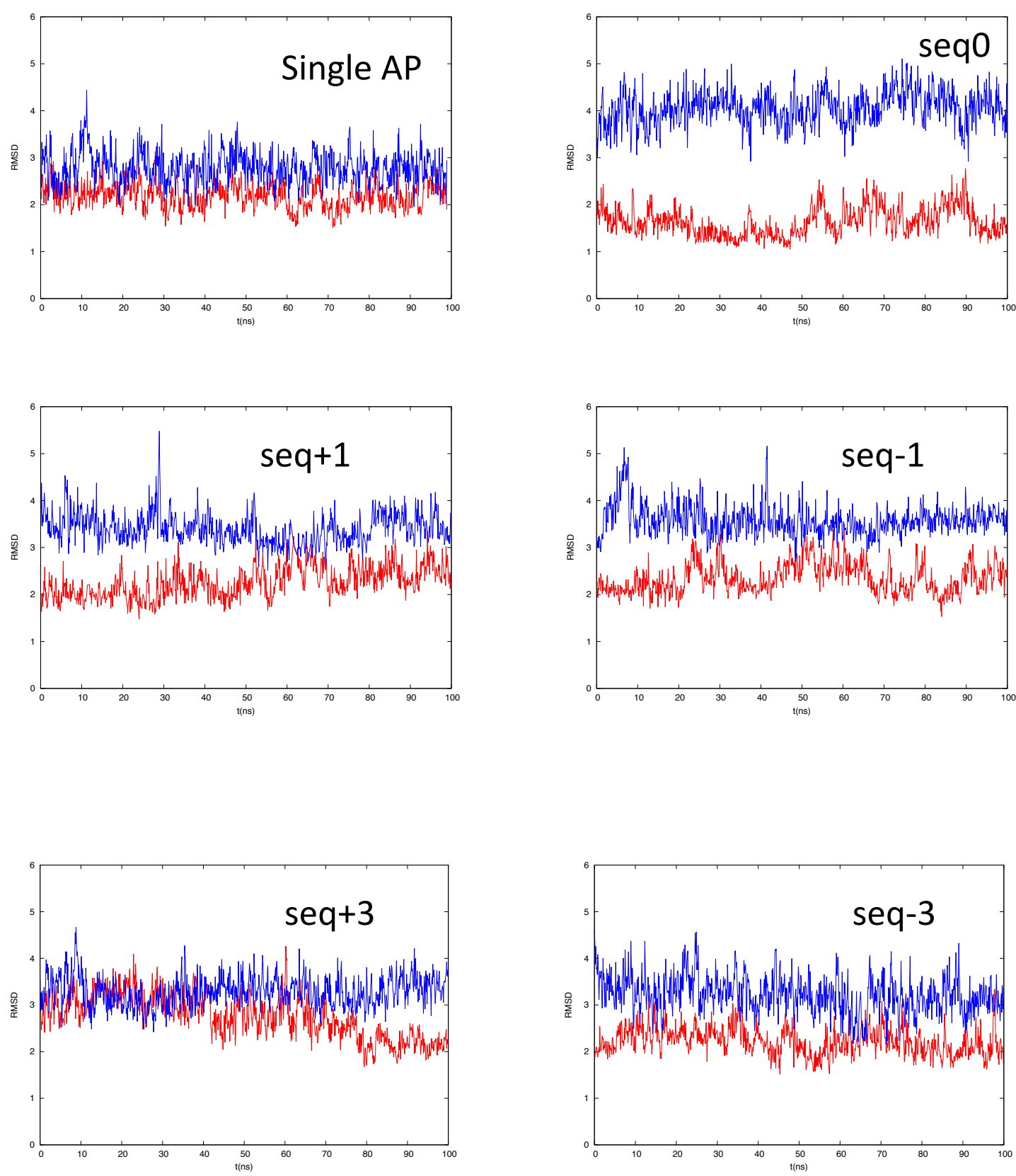

Figure S7) Time series of the Root mean Square Deviation (RMSD) in $\AA$ with respect to the crystal structure for the single containing and clustered AP lesions, inside the APE1 complex (red) and in solution (blue), see Figure 4 of the main text for the corresponding distribution. 


\section{References:}

1. Mol, C. D.; Izumi, T.; Mitra, S.; Tainer, J. A. DNA-Bound Structures and Mutants Reveal Abasic DNA Binding by APE1 and DNA Repair Coordination [Corrected]. Nature 2000, 403 (6768), 451-456.

2. Jorgensen, W. L.; Chandrasekhar, J.; Madura, J. D.; Impey, R. W.; Klein M. L. Comparison of simple potential functions for simulating liquid water, J. Chem. Phys. $1993,79,926-935$.

3. Wang, J.; Wolf, R. M.; Caldwell, J. W.; Kollman, P. A.; Case, D. A. Development and testing of a general amber force field. J. Comput. Chem. 2004, 25, 1157-1174.

4. Bayly, C. I.; Piotr, C.; Cornell, W. D.; Kollman, P. A. Well-Behaved Electrostatic Potential Based Method Using Charge Restraints for Deriving Atomic Charges: The RESP Model. J. Phys. Chem. 1993, 97, 10269-10280.

5. Phillips, J. C.; Braun, R.; Wang, W.; Gumbart, J.; Tajkhorshid, E.; Villa, E.; Chipot, C.; Skeel, R. D.; Kale, L.; Schulten, K. J. Comp. Chem. 2005, 26, 1781-1802.

6. Cornell, W. D.; Cieplak, P.; Bayly, C. I.; Gould, I. R.; Merz, K. M.; Ferguson, D. M.; Spellmeyer, D. C.; Fox, T.; Caldwell, J. W.; Kollman, P. A. A Second Generation Force Field for the Simulation of Proteins, Nucleic Acids, and Organic Molecules. J. Am. Chem. Soc. 1995, 117, 5179-5197.

7. Ivani, I.; Dans, P. D.; Noy, A.; Pérez, A.; Faustino, I.; Hospital, A.; Walther, J.; Andrio, P.; Goñi, R.; Balaceanu, A.; Portella, G.; Battistini, F.; Gelpí, J. L.; González, C.; Vendruscolo, M.; Laughton, C. A.; Harris, S. A.; Case, D. A.; Orozco, M. Parmbsc1: A 
Refined Force Field for DNA Simulations. Nat. Methods, 2015, 13, 55-58.

8. Feller, S. E.; Zhang, Y.; Pastor, R. W.; Brooks, B. R. Constant pressure molecular dynamics simulation: The Langevin piston method. J. Chem. Phys. 1995, 103, 46134621.

9. Darden, T.; York, D.; Pedersen, L. Particle mesh Ewald: An N-log(N) method for Ewald sums in large systems. J. Chem. Phys. 1993, 98, 10089-10092.

10. Humphrey, W.; Dalke, A.; Schulten, K. VMD - Visual Molecular Dynamics. J. Molec. Graphics, 1996, 14, 33-38.

11. Pettersen E. F.; Goddard T. D.; Huang C. C.; Couch G. S.; Greenblatt D. M.; Meng E. C.; Ferrin T. E. UCSF Chimera--a visualization system for exploratory research and analysis. J. Comput. Chem. 2004, 25(13), 1605-1612. 